\title{
Metode Analisis Muatan Literasi Sains pada Buku Ajar Tematik Sekolah Dasar/Madrasah Ibtidaiyah (Studi Deskriptif Pada Buku Tematik Kelas 4 Tema 1)
}

\author{
Kartika Metafisika1, Husni Abdillah² \\ 1STAI Taruna Surabaya, Indonesia \\ 2UIN Sunan Ampel Surabaya, Indonesia
}

\begin{tabular}{l} 
A) Check for updates open access \\
\hline Sections Info \\
\hline Article history: \\
Received: Nopember 252020 \\
Accepted: Nopember 272020 \\
Published online: Desember 30 \\
2020 \\
\hline Keywords: \\
Science Literacy \\
Knowledge of Science (KoS) \\
Nature of Science (NoS) \\
Science as The Way of Thinking \\
(WoT) \\
Science Technology Society \\
(STS) \\
the characteristics of sound \\
Thematics Elementary Texbook
\end{tabular}

DOI : 10.47400/jiees.v1i2.26

\begin{abstract}
This study aims to understand how to analyze literacy content in Natural Sciences (IPA) textbooks. The analysis was carried out on the thematic textbook of curriculum 2013 class 4th entitled "Indahnya Kebersamaan". The research was conducted using a qualitative descriptive method by mapping Knowledge of Science (KoS), Nature of Science (NoS), Science as The Way of Thinking (WoT), and Science Technology Society (STS) as elements that need to be met in IPA textbooks based on scientific literacy criteria build by Chiapetta. Based on the results of the search, it is known that the Thematic Book for class 4 Theme 1 has generally fulfilled the elements of scientific literacy.
\end{abstract}

\section{INTRODUCTION}

Dalam menghadapi persaingan dan kolaborasi global di masa depan, pembelajaran Sekolah Dasar/Madrasah Ibtidaiyah saat ini dikembangkan untuk menghadapi tantangan internal yaitu untuk memenuhi kebutuhan usia produktif, dan tantangan eksternal berhubungan dengan kebangkitan industri kreatif, majunya teknologi informasi dan budaya, permasalahan lingkungan hidup, serta perkembangan pendidikan tingkat internasional (Permendikbud 2013) melalui kurikulum 2013.

Dalam kurikulum 2013, berbagai mata pelajaran dipadukan sehingga siswa diharapkan dapat memahami secara komprehensif peran dan manfaat dari tiap-tiap mata pelajaran yang terrangkum dalam pembelajaran tematik. Selain itu, pembelajaran tematik juga mengaitkan konteks sehari-hari dengan ilmu pengetahuan yang dipelajari oleh para pemikir dan ilmuwan melalui berbagai model, metode, dan pendekatan pembelajaran yang mendukung.

Khusus dalam pelaksanaan pembelajaran yang berhubungan dengan Ilmu Pengetahuan Alam (IPA), siswa diharapkan memiliki kemampuan literasi sains sehingga siswa memahami peran IPA dalam kehidupan bermasyarakat dan mendukung kemajuan peradaban. Literasi sains sangat penting dikuasai oleh siswa dalam kaitannya dengan bagaimana mereka melihat lingkungan, kesehatan, ekonomi, dan masalah masyarakat modern bergantung pada teknologi dan kemajuan dan perkembangan ilmu pengetahuan ${ }^{1}$ (Rusilowati et al. 2016). Meski demikian, 
kemampuan berliterasi sains bukanlah hal yang mudah untuk dicapai karena dalam memahami materi IPA yang abstrak sehingga sulit dipahami, dibutuhkan keterampilan berpikir tingkat tinggi yang perlu ditingkatkan dengan media, model, pendekatan, dan metode pembelajaran yang mendukung literasi sains.

Menurut OECD (1999) Literasi sains menggunakan pengetahuan sains untuk mengidentifikasi pertanyaan dan menggambarkan kesimpulan berdasarkan bukti, mengetahui dan membantu membuat kesimpulan terhadap alam sekitar dan perubahannya yang dilakukan oleh aktifitas manusia (OECD 1999), selanjutnya OECD mengembangkan definisi literasi sains sebagai kecakapan sains serta pengetahuan untuk mengidentifikasi pertanyaan, memperoleh pengetahuan yang baru, menjelaskan fenomena sains, memperoleh simpulan berdasar fakta, memahami karakteristik sains, kesadaran bagaimana sains dan teknologi membentuk lingkungan alam, intelektual, dan budaya, serta kemauan untuk terlibat dan peduli terhadap isu-isu yang terkait sains (OECD 2016).

Melihat perkembangan definisi literasi sains, maka sains tidak hanya merupakan objek pendidikan tetapi juga sebagai proses pembelajaran itu sendiri. Definisi literasi dibagi ke dalam tiga aspek yaitu konteks sains, konsep sains, dan konten atau situasi (OECD 1999; OECD 2016; Holbrook \& Rannikmae 2009) :

a. Konsep sains.

Konsep sains adalah yang terpenting dalam domain literasi sains untuk memahami fenomena di alam dan perubahannya yang disebabkan oleh aktivitas manusia.

b. Proses sains.

Proses sains berpusat pada kemampuan untuk melihat, menginterpretasi, dan bertindak berdasarkan bukti. Lima proses sains menurut OECD/PISA dalam Holbrook dan Rannikmae (2009) berkaitan dengan:

- Mengenal pertanyaan ilmiah

- Identifikasi bukti

- Membuat kesimpulan

- Mengomunikasikan kesimpulan

- Mendemonstrasikan pemahaman terhadap konsep

Dalam proses asesmennya, proses sains harus mengacu pada konsep sains.

Buku ajar tematik yang diterbitkan oleh Menteri Pendidikan dan Kebudayaan adalah bahan ajar dan media pembelajaran yang berperan sangat penting dalam membantu guru mengejawantahkan pembelajaran mengacu pada kurikulum 2013. Dalam buku ajar tematik, guru dibimbing dalam memahami silabus hingga pembuatan rencana pembelajaran agar mendukung terlaksananya kurikulum 2013 dari segi konten maupun proses pembelajarannya. Buku ajar ini pun digunakan oleh SD/MI senasional, sehingga dampak pengaplikasian buku ini dalam pembelajaran akan dirasakan oleh guru maupun siswa yang terlibat dalam pembelajaran skala luas.

Penelitian ini bertujuan untuk memahami metode analisis muatan literasi sains dalam Buku Ajar Tematik Sekolah Dasar/Madrasah Ibtidaiyah kelas 4 Tema 1 edisi revisi 2017 yang berjudul Indahnya Kebersamaan. Garcia (1985) melakukan pengategorian terhadap muatan literasi sains dalam buku teks mengacu pada aspekaspek yang harus dipenuhi dalam literasi sains mengacu pada sifat sains (nature of science) dan masih relevan dengan konteks literasi sains saat ini sehingga masih 
digunakan untuk analisis buku teks berbasis literasi sains (Chiappetta et al. 1993; Wilkinson 1999; Chiappetta \& Fillman 2007; Nurfaidah 2017; Ardianto \& Pursitasari 2017) yakni:

1. Sains sebagai pengetahuan/Knowledge of Science (KoS).

Materi buku teks dalam kategori ini memiliki kriteria:

a) Berupa fakta, konsep, prinsip, dan hukum;

b) terdapat fakta, teori, dan model; dan

c) bertanya kepada siswa untuk mengungkapkan kembali informasi dan pengetahuan.

2. Menyelidiki sifat sains/ Nature of Science (NoS)

Kategori ini terdapat kalimat yang menstimulasi berpikir dan melakukan sesuatu untuk mendapatkan jawaban dengan merefleksikan pembelajaran aktif dan aspek inkuiri. Contoh kriteria menyelidiki sifat sains yakni:

a) menyediakan pertanyaan penelitian melalui penggunaan alat,

b) mengajak siswa menjawab pertanyaan dengan tabel dan grafik,

c) berisi pertanyaan yang mengajak pembaca untuk berhitung,

d) membantu siswa untuk mencari alasan dari suatu jawaban, dan

e) mengajak siswa bereksperimen

3. Sains sebagai cara Berpikir /Science as The Way of Thinking (WoT)

Kategori ini menunjukkan bagaimana saintis melakukan suatu penemuan dan eksperimen. Kriteria dari kategori ini diantaranya:

a) Menunjukkan bagaimana saintis melakukan eksperimen;

b) Menunjukkan sejarah perkembangan suatu ide;

c) Menekankan pada pengalaman empiris dan objektifitas dari sains;

d) Menggambarkan penggunaan asumsi;

e) Menunjukkan bagaimana ilmu pengetahuan dibentuk melalui pemikiran secara deduktif dan induktif;

f) Menunjukkan hubungan sebab akibat;

g) Mendiskusikan bukti; dan

h) Menunjukkan bagaimana sains adalah ilmu untuk menguji diri.

4. Interaksi sains, teknologi, dan masyarakat/Science Technology Society (STS)

Kategori ini berisikan tentang bagaimana teks menggambarkan dampak perkembangan sains di masyarakat. Kriteria dari kategori ini yaitu:

a) Menunjukkan penggunaan sains dan teknologi di masyarakat,

b) Penekanan efek negatif dari perkembangan sains dan teknologi di masyarakat,

c) Mendiskusikan isu sosial yang berhubungan dengan sains dan teknologi,

d) Menunjukkan karir dan pekerjaan di bidang sains dan teknologi.

Pertimbangan dalam pemilihan buku ini adalah didasarkan pada rentang umur siswa kelas 4 yaitu kisaran 10-11 tahun. Pada kisaran umur tersebut, berdasarkan teori piaget, siswa masuk ke dalam tahap operasi berpikir formal yaitu siswa mampu berpikir secara abstrak dan logis, serta mengambil kesimpulan berdasarkan informasi yang ada (Mukhlisah 2015) sehingga diharapkan pada tahap ini konsep abstrak dan proses pembelajaran sains dapat dipahami oleh siswa sesuai kemampuan kognitifnya. 
Dengan menerapkan metode analisis muatan literasi sains pada buku ajar tematik yang digunakan oleh guru dan siswa di seluruh sekolah di indonesia, diharapkan dapat memberikan kontribusi dalam mengukur sejauh mana buku ajar tematik sebagai sumber belajar dan media pembelajaran, dapat mendukung penerapan literasi sains dalam Kurikulum 2013. Dengan demikian sebagai langkah awal penelitian analisis buku literasi sains, peneliti mencoba mencari tahu bagaimana cara memetakan muatan literasi sains dalam Buku Ajar Tematik Sekolah Dasar/Madrasah Ibtidaiyah kelas 4 Tema 1 dan bagaimana penerapan literasi sains dalam Buku Ajar Tematik Sekolah Dasar/Madrasah Ibtidaiyah kelas 4 Tema 1.

\section{RESEARCH METHOD}

\section{General Background}

Penelitian ini masuk dalam jenis penelitian deskriptif menggunakan metode analisis konten. Analisis konten adalah metode penelitian yang digunakan pada penelitian sosial untuk menguantifikasi pesan dan simbol yang terdapat di media seperti buku, televisi, koran, dan lain sebagainya (Wilkinson 1999). Metode penelitian ini dapat diterapkan dalam penelitian kualitatif, kuantitatif, dan penelitian mix-method dan menggunakan berbagai teknik analitis untuk menghasilkan temuan dan memasukkannya ke dalam konteks (White \& Marsh 2006).

\section{Sample}

Objek penelitian berupa buku teks tematik Sekolah Dasar Tema 7 yang berjudul Cita-citaku karangan Kemendiknas.

\section{Procedures}

Penelitian dengan metode analisis konten dilakukan dengan melakukan teknik sampling, mengumpulkan data, analisis data, dan pelaporan hasil analisis. Data yang dikumpulkan merupakan unit-unit yang digabungkan ke dalam satu atau lebih kategori yang ingin diteliti (White \& Marsh 2006).

Prosedur penelitian yang digunakan mengacu pada prosedur yang digunakan oleh Chiapetta et. al (2004) dalam Chiappetta \& Fillman (2007) dan Chiappetta et al. (1993).

a. Memahami kerangka konseptual untuk mendefinisikan kategori literasi sains/nature of science dan kriteria dari masing-masing kategori untuk dianalisis. Kategori yang digunakan oleh Garcia (1985) adalah a) sains sebagai pengetahuan; b) menyelidiki sifat sains, c) sains sebagai cara berpikir, dan d) interaksi sains, teknologi, dan masyarakat. Dengan kriteria yang telah dijelaskan pada bab 2.

b. Mendefinisikan unit yang dianalisis untuk dikategorisasikan pada buku teks.

Unit yang dianalisis adalah seluruh komponen IPA yang muncul dalam buku tematik.

c. Realibilitas dilakukan dengan mendiskusikan hasil analisis antara peneliti satu dengan peneliti kedua untuk mendapatkan kesepaktan tentang penerapan kriteria. 


\section{RESULTS AND DISCUSSION}

Buku yang dianalisis merupakan buku tematik terbitan Mendikbud yang secara resmi digunakan oleh seluruh Sekolah Dasar Negeri di Indonesia pada tahun ajaran 2017-2018. Muatan buku tematik SD/MI direvisi setiap tahun sehingga perlu ditekankan bahwa buku teks yang digunakan adalah buku tematik SD/MI revisi 2017 kelas 4 tema 1: Indahnya Kebersamaan. Pada kurikulum 2013, pembelajaran IPA di SD/MI dilaksanakan terintegrasi dengan mata pelajaran lainnya mulai dari kelas 4 hingga kelas 6. Pada buku yang dianalisis diketahui bahwa Kompetensi Dasar IPA yang perlu dicapai pada ranah pengetahuan 3.6 Menerapkan sifat-sifat bunyi dan keterkaitannya dengan indera pendengaran dan ranah keterampilan yakni 4.6 Menyajikan laporan hasil percobaan tentang sifat-sifat bunyi.

Untuk mengetahui bagaimana Knowledge of Science (KoS), Nature of Science (NoS), Science as Way of Thinking (WoT), dan Science Technology Society (STS) terdistribusi dalam pembelajaran IPA di buku tematik, maka peneliti membuat Tabel 2 sebagai berikut:

Tabel 2. Pemetaan Literasi Sains dalam Buku Tematik

\begin{tabular}{llllll}
\hline $\begin{array}{l}\text { Subtema/ } \\
\text { Pembelajaran } \\
\text { ke- }\end{array}$ & $\begin{array}{l}\text { Indikator } \\
\text { Pembelajaran }\end{array}$ & $\begin{array}{l}\text { Pemataan Literasi Sains / } \\
\text { Halaman buku }\end{array}$ & \multicolumn{2}{l}{$\begin{array}{l}\text { Memenuhi } \\
\text { Literasi } \\
\text { Sains }\end{array}$} \\
\cline { 2 - 6 } & & KoS NoS NoT & STS & Ya Tidak
\end{tabular}

Berdasarkan hasil analisis yang dapat dilihat pada lampiran 1, tiap materi IPA terdistribusi pada masing-masing pembelajaran di tiap subtema. Berikut ini adalah hasil analisis yang didapat:

1. Subtema 1: Keberagaman Budaya Bangsaku

a. Pembelajaran 1

Pada subtema 1 pembelajaran 1 seluruh unsur literasi sains sudah termuat. Pada unsur STS konteks yang digunakan adalah alat musik tradisional untuk kemudian mengarah pada pembahasan IPA mengenai bunyi. Selanjutnya siswa mengamati tiap alat musik kemudian anak diminta untuk menganalisis bagaimana bunyi bisa dihasilkan dari tiap-tiap alat musik (NoS) lalu anak diminta untuk mencatat hasil pengamatan dan mengambil kesimpulan, kemudian anak diminta berpikir kritis (WoT) untuk menjawab bagaimana agar suara dapat terdengar lebih pelan maupun lebih kencang. Terakhir dikemukakan konsep dari bagaimana bunyi dapat didengar oleh telinga karena adanya getaran pada benda/materi sehingga mengakibatkan gelombang bunyi di udara (KoS).

b. Pembelajaran 3

Pada subtema 1 pembelajaran 3 seluruh unsur literasi sains sudah termuat. Konsep tentang bagaimana bunyi merambat telah dijelaskan pada pembelajaran subtema 1 pembelajaran $1(\mathrm{KoS})$ yang kemudian dibuktikan melalui tiga percobaan yakni anak diminta untuk menjawab pertanyaan "bagaimana bunyi dapat sampai ke 
telinga kita?" dan untuk menjawabnya anak melakukan percobaan membuat telepon sederhana dengan media selang (untuk membuktikan bahwa bunyi merambat melalui udara), dan kawat/benang (untuk membuktikan bahwa bunyi merambat melalui zat padat), dan air (untuk membuktikan bahwa bunyi merambat melalui zat cair) (NoS). Untuk media yang digunakan dalam percobaan, STS muncul dengan memanfaatkan permainan tradisional yang pernah populer yakni telepon-teleponan menggunakan kaleng dan kawat, dan keseluruhan proses pembelajaran ini melibatkan keterampilan berpikir tingkat tinggi karena siswa diharapkan mampu membuat laporan hasil percobaan (WoT).

\section{Subtema 2: Kebersamaan dalam Keberagaman}

a. Pembelajaran 1

Pada subtema 2 pembelajaran 1 seluruh unsur literasi sains terpenuhi. Pertama-tama anak diminta untuk membuat percobaan dan laporan percobaan mengenai arah rambat bunyi (NoS), kemudian guru mengingatkan kembali mengenai bagaimana bunyi dapat didengar oleh gendang telinga disertai penguatan konsep yang dipelajari pada subtema sebelumnya tentang bagaimana bunyi terbentuk (KoS). WoT muncul dari proses penemuan dan pembuatan laporan karena melibatkan keterampilan berpikir tingkat tinggi.

b.Pembelajaran 3

Pada subtema 2 pembelajaran 3 seluruh unsur literasi sains terpenuhi jika dikaitkan dengan pembelajaran sebelumnya. Pada subtema ini anak diharapkan mampu untuk mereview kembali pemahaman mereka tentang bagaimana bunyi terbentuk, macammacam media rambat bunyi, dan arah rambat bunyi (WoT dan KoS). Anak juga diharapkan mampu untuk melaksanakan percobaan yang berbeda untuk mendapatkan kesimpulan yang sama mengenai arah rambat bunyi (NoS). untuk STS anak diminta untuk mencari tahu cara merawat telinga agar pendengaran berfungsi maksimal.

3. Subtema 3: Bersyukur atas Keberagaman

a. Pembelajaran 1

Pada subtema 3 pelajaran 1 unsur NoS, WoT, dan STS muncul secara eksplisit di buku sedangkan KoS muncul dalam proses pembelajaran sebagai hasil kesimpulan dari percobaan. Pertama-tama Anak diminta melakukan percobaan untuk memahami bahwa bunyi dapat diserap dan dipantulkan (NoS). Berdasarkan Kegiatan tersebut anak diharapkan melibatkan keterampilan berpikir tingkat tinggi dalam melaksanakan percobaan hingga pembuatan laporan. STS muncul dengan memanfaatkan alat-alat yang dapat dibutuhkan sehari-hari dalam percobaan. Unsur KoS muncul tidak secara tersirat dalam subtema 1 pembelajaran 1 melainkan dalam proses pembelajaran ketika perumusan kesimpulan.

b.Pembelajaran 3

Pada subtema 3 pelajaran 3 keseluruhan unsur terpenuhi. Anak diminta melakukan percobaan untuk memahami sifat bunyi bahwa bunyi dapat diserap dan dipantulkan (KoS) sedangkan WoT muncul ketika anak melakukan percobaan dan menulis laporan karena membutuhkan keterampilan berpikir tingkat tinggi. KoS tidak secara eksplisit ditunjukkan dalam buku siswa melainkan muncul sebagai kesimpulan dalam proses pembelajaran, sedangkan STS ditunjukkan dengan memberikan contoh 
mengenai pemantulan dan penyerapan bunyi dalam konteks yang dapat diamati sehari-hari

\section{CONCLUSIONS}

Berdasarkan hasil analisis diketahui bahwa Buku Tematik kelas 4 Tema 1 secara umum telah memenuhi unsur-unsur literasi sains. Sains sebagai proses muncul melalui percobaan hingga membuat laporan percobaan dan terakhir anak membuat kesimpulan berupa konsep tentang sifat-sifat bunyi (NoS). Sedangkan WoT secara implisit muncul karena pembelajaran melibatkan proses berpikir tingkat tinggi melalui percobaan dan pengambilan kesimpulan dari percobaan yang dilaksanakan, selain itu anak diarahkan untuk berpikir konvergen dan divergen secara berkesinambungan. Hal ini terlihat dari proses berpikir yang ditunjukkan pada tema 1 secara utuh yakni untuk mencari jawaban dari percobaan kemudian dari hasil percobaan sebelumnya anak diminta untuk membuktikan lagi dalam percobaan lainnya dengan konsep yang sama. STS muncul karena pembelajaran dilaksanakan terintegrasi dengan pelajaran lain sehingga siswa memahami fungsi IPA dalam keseharian. Dan Terakhir adalah Konsep yang dimunculkan dari proses pembelajaran IPA dimunculkan tersirat dalam pembelajaran.

Langkah-langkah analisis ini dapat dijadikan pedoman dalam menganalisis muatan literasi sains untuk buku teks IPA atau buku pembelajaran tematik lainnya. Selain didapatkan gambaran untuh bagaimana pelaksanaan literasi sains dalam kurikulum 2013, proses analisis ini dapat digunakan sebagai pedoman untuk mendesain muatan buku teks IPA.

\section{ACKNOWLEDGEMENTS}

Penulis mengucapkan terima kasih yang sebesar-besarnya kepada STAI Taruna Surabaya dan UIN Sunan Ampel Surabaya atas dukungan dan bantuan dalam menyelesaikan jurnal penelitian ini.

\section{REFERENCES}

Ardianto, D. \& Pursitasari, I.D., 2017. Do Middle School Science Textbook Enclose an Entity of Science Literacy? ,1(1), pp.24-27.

Chiappetta, E.L. \& Fillman, D.A., 2007. Analysis of five high school biology textbooks used in the United States for inclusion of the nature of science. International Journal of Science Education, 29(15), pp.1847-1868.

Chiappetta, E.L., Sethna, G.H. \& Fillman, D.A., 1993. Do middle school life science textbooks provide a balance of scientific literacy themes? Journal of Research in Science Teaching, 30(7), pp.787-797.

Garcia, T.D.., 1985. An analysis of earth science textbooks for presentation of aspects of scientific literacy. University of Houston, Texas.

Holbrook, J. \& Rannikmae, M., 2009. The Meaning of Scientific Literacy. NInternational Journal of Environmental and Science Education, 4(July), pp.275-288.

LKPP-UNHAS, 2015. Bahan Ajar, Buku Ajar, Modul, dan Panduan Praktik,

Mukhlisah, A., 2015. Perkembangan Kognitif Jean Pieget dan Peningkatan Belajar Anak 
Diskalkulia. Jurnal Kependidikan Islam, 6, pp.118-143.

Nurfaidah, S.S., 2017. Analisis Aspek Literasi Sains Pada Buku Teks Pelajaran IPA Kelas V SD. Mimbar Sekolah Dasar, 4(1), pp.56-66.

OECD, 1999. Measuring Student Knowledge and Skills: A New Framework for Assessment. Oecd, p.85.

OECD, 2016. PISA 2015 Assessment and Analytical Framework: SCIENCE, READING, MATHEMATIC AND FINANCIAL LITERACY, Paris: OECD Publishing.

Permanasari, A., 2014. Kurikulum 2013: Implikasinya dalam Pembelajaran di Sekolah, Pendidikan Profesi dan Pendidikan Tinggi. In Proceeding Seminar Nasional: Cokroaminoto Palopo University Journal. p. 1. Available at: https://journal.uncp.ac.id/index.php/proceding/article/view/218/207.

Permendikbud, 2013. Peraturan Menteri Pendidikan dan Kebudayaan Republik Indonesia Nomor 70 Tahun 2013 Tentang Kerangka Dasar dan Struktur Kurikulum Sekolah Menengah Kejuruan/Madrasah Aliyah Kejuruan.

Rusilowati, A. et al., 2016. Developing an instrument of scientific literacy asessment on the cycle theme. International Journal of Environmental and Science Education, 11(12), pp.5718-5727.

TIM GLN Kemendikbud, 2017. Gerakan Literasi Nasional: Materi Pendukung Literasi Sains, Jakarta: Kementrian Pendidikan dan Kebudayaan.

Wahyuni, H.T., Setyosari, P. \& Kuswandi, D., 2016. IMPLEMENTASI PEMBELAJARAN TEMATIK KELAS 1 SD. edcomtech, 1(2), pp.129-136.

White, M.D. \& Marsh, E.E., 2006. Content Analysis: A Flexible Methodology. Library Trends, 55(1), pp.22-45. Available at: http://muse.jhu.edu/content/crossref/journals/library_trends/v055/55.1white.h tml.

Wilkinson, J., 1999. A Quantitative Analysis of Physics Textbooks for Scientific Literacy Themes. Research in Science Education, 29(3), pp.385-399. Available at: http://www.springerlink.com/index/10.1007/BF02461600.

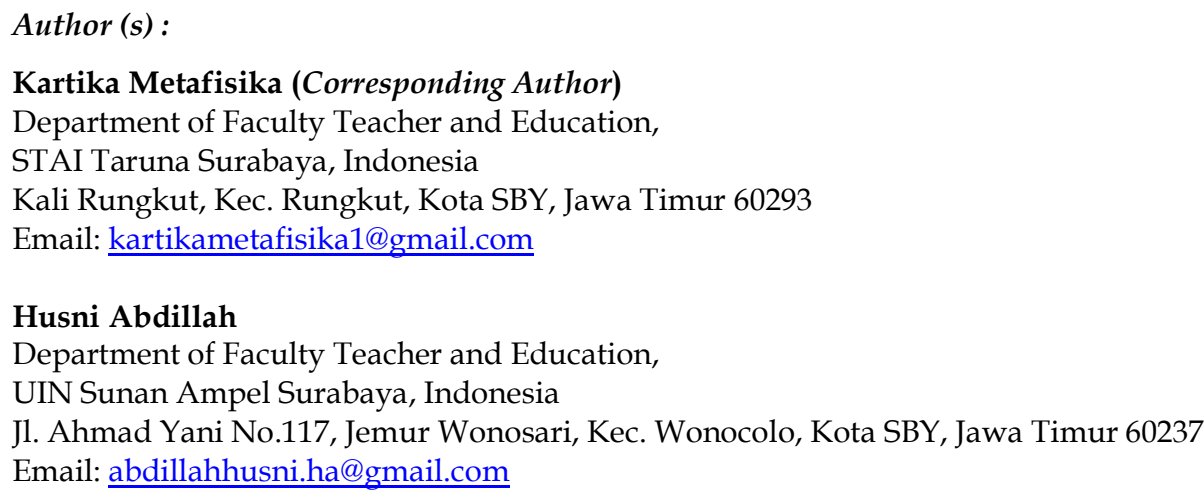


JIEES : Journal of Islamic Education at Elementary School Homepage : http://jiees.alkhoziny.ac.id/index.php/jiees Email : jiees@alkhoziny.ac.id
p-ISSN : 2723 -7184; e-ISSN : 2723-8148 JIEES, Vol. 1, No.2, Desember 2020 : 111-119

(C) 2020 JIEES : 